EDITORIAL

\title{
The tobacco industry in Asia: revelations in the corporate documents
}

\section{J M Mackay}

Tobacco Control 2004;13(Suppl II):ii1-ii3. doi: 10.1136/tc.2004.010082

$\mathrm{S}$ cholarship on tobacco industry documents has concentrated on the west. There have been two previous supplements on the documents published by Tobacco Control, which focused on the USA in $2002^{1}$ and on Australia in 2003, ${ }^{2}$ as well as many individual papers. Hirschhorn has assembled a list of all publications that deal principally with the documents. ${ }^{3}$

This supplement contains the first collection of papers addressing Asian documents, which include diverse countries such as Cambodia, China, Hong Kong SAR, Indonesia, Japan, Malaysia, the Philippines, Singapore, and Thailand, with topics ranging from smuggling and subversion of proposed legislation to tobacco industry youth campaigns (see below).

This is not just an issue of academic inclusion; these articles represent a rare resource enabling governments, health advocates, and the media to gain an unprecedented insight into the minds, motives, strategies, tactics, and data of the tobacco industry. Appreciation of tobacco industry strategies over the past decades is essential for Asian countries to formulate an appropriate legislative and public policy response. ${ }^{4}$

It might be argued that some of the information revealed could be classified as "normal business practices" in the marketing strategy of any company. However, the fundamental harmfulness of the product taken with the industry's lobbying and public relations tactics makes these industry documents compelling.

Obstacles to tobacco control in Asia that were once puzzling may now be understood. The industry infiltrated some of the most respected scientific institutions (such as universities), and scientists who argued against the scientific evidence on the damaging effects of tobacco are now known to have been paid to do so. ${ }^{5}$

These tactics of the industry have, in general, been highly successful. In spite of decades of knowledge, World Health Assembly resolutions, World Health Organization plans including five year Regional Action Plans for Asia since 1990, numerous regional and national conferences and declarations, the number of smokers is increasing in Asia, more smokers are dying, children are still taking up smoking, ${ }^{6}$ including more girls, ${ }^{7}$ and the economic costs are both substantial and escalating. ${ }^{8}$

A note of caution needs to be sounded. These documents inevitably portray only the industry perspective and thus may convey glowing reports of successful meetings and negotiations, in particular where information was relayed back to headquarters. The other party at the meeting, for example, a government official, might report a quite different perspective on what was discussed, or the conclusion of the meeting. Activists might feel that their important role is ignored in the documents, although there is a grudging compliment from the industry that "...the anti-smoking lobby has made significant gains in all countries throughout the region". And, in spite of these efforts by the tobacco industry, a raft of successful legislation has been passed in Asia over the last 20 years.

Industry documents have already provided key information to countries and activists around the world, and have been used as an advocacy tool in places as diverse as Guatemala, Hong Kong, and South Africa. Each nation needs to access its own country's documents so that governments may fully understand the tactics of the tobacco industry in their own country. Only in this way will they be better prepared to introduce public health policies to improve the health of their citizens and, in particular, to protect their children. ${ }^{9}$

This collection of documents represents the first coordinated attempt to collate some of the information on Asian countries, already home to half the world's smokers, and the major growth area for the industry in the future. Delegates at the Asian Pacific Association for the Control of Tobacco (APACT) conference held from 15-18 September 2004 in Gyeongju, Korea, wholeheartedly endorsed and welcomed this forthcoming supplement, believing it will be of great benefit in their work on tobacco control.

Authors and reviewers alike commented that with the word limit constraints imposed by journals, it is never possible to do justice to every conceivable angle and episode surrounding events that sometimes stretched over decades. Millions of pages remain unexamined and more revelations will be forthcoming on the countries covered in this supplement and in other countries.

The authors are to be congratulated in unearthing this wealth of detail on tobacco industry behaviour in Asia. The US National Institutes of Health, the Rockefeller Foundation's Trading Tobacco for Health initiative, and the Australian National Health and Medical Research Council are to be commended for supporting the research for these papers.

\section{HIGHLIGHTS FROM THE PAPERS IN THIS SUPPLEMENT}

- "Care and feeding": The Asian environmental tobacco smoke consultants programme describes the tobacco industry's Asian ETS consultants programme in three key places: China, Hong Kong, and Malaysia. The programme was successful in blurring the science on ETS and dissuading national policy makers from instituting comprehensive bans on smoking in public places.

- "A phony way to show sincerity, as we all well know": tobacco industry lobbying against tobacco control in Hong Kong. The strategies of the transnational tobacco companies to delay and frustrate the government's policymaking process are identified and analysed. An appreciation of industry's tactics can assist policymakers in other nations understand better the opposition they may encounter. 


\section{Background}

The 1998 Minnesota lawsuit in the USA against the tobacco industry was settled on terms highly favourable to the plaintiffs. The lawsuit's most significant result was not the large financial settlement or the banning of all advertising and promotion within Minnesota, but the disclosure of millions of previously confidential tobacco industry documents. ${ }^{10}$ The documents are available in warehouses in Minnesota, USA and in Guildford, England. They are also available on tobacco industry websites and several health sites dedicated to making the documents more user friendly. The documents are a collection of letters, memos, studies, reviews of studies, marketing plans, statements of policy, article reprints and news clippings, on a wide range of topics. The documents provide information that is not available from any other source and describe the history of industry activities over the past 50 years. ${ }^{11}$

- "Asian yuppies...are always looking for something new and different": creating a tobacco culture among young Asians shows that industry used six vehicles to construct a culture of tobacco: music, entertainment, sport, adventure, glamour, and independence.

- "Asia is now the priority target for the world antitobacco movement": attempts by the tobacco industry to undermine the Asian anti-smoking movement identifies and examines the strategies utilised by Asian based multinational tobacco companies in discrediting the region's anti-tobacco activists.

- Industry sponsored youth smoking prevention programme in Malaysia: a case study in duplicity. The tobacco industry bought into the youth smoking issue and thus sought to move higher on the moral playing field and strengthen its relationship with government, while at the same time continuing to market to youth. There is no evidence that industry youth smoking prevention programmes were effective in reducing smoking; however they were effective in diluting the government's tobacco control legislation.

- A mire of highly subjective and ineffective voluntary guidelines: tobacco industry efforts to thwart tobacco control in Malaysia. Commencing in the 1970s, the industry began to systematically thwart government tobacco control. Guidelines were successfully promoted in the place of legislation for over two decades. Even when the government succeeded in implementing regulations such as health warnings and advertising bans they were compromised and acted effectively to retard further progress for years.

- "The world's most hostile environment": how the tobacco industry circumvented Singapore's advertising ban. The comprehensive prohibition on advertising did not prevent the companies from advertising cigarettes to Singaporeans, using neighbouring Malaysian television. To launch a new brand of cigarettes, Alpine, Philip Morris used a non-tobacco product, the Alpine wine cooler, and other creative strategies.

- A "clean cigarette" for a clean nation: a case study of Salem Pianissimo in Japan. RJ Reynolds successfully launched its "clean" cigarette aiming to exploit perceived cultural characteristics such as a penchant for cleanliness, an eagerness to try new products, and social harmony.

- The tobacco industry's accounts of refining indirect tobacco advertising in Malaysia shows how when faced with an advertising ban, the tobacco companies will create ways to circumvent it, such as trademark diversification.

- The Philippine tobacco industry: "the strongest tobacco lobby in Asia". As in other parts of Asia, a prominent scientist recruited by the industry publicly repudiated links between smoking and disease. The placement of health warning labels was negotiated to benefit the industry and the commercial environment allowed it to capitalise on their marketing freedoms to the fullest potential. The Philippines has seen some of the world's most extreme and controversial forms of tobacco promotion flourish.

- "If we can just 'stall' new unfriendly legislations, the scoreboard is already in our favour": transnational tobacco companies and ingredients disclosure in Thailand. Ingredient disclosure in the Tobacco Products Control Act was identified by transnational tobacco companies not only as a significant threat to their operations in Thailand, but also as a dangerous global precedent. Industry documents reveal a determined campaign to block, stall, or amend the proposed regulation during the legislative process. As submission of ingredient lists appeared unavoidable, leading companies endeavoured to confound the disclosure requirement by disguising ingredients and reformulating brand recipes.

- Breaking and re-entering: British American Tobacco in China 1979-2000 is the first detailed analysis of previously unseen documents focusing on the tactics used by British American Tobacco (BAT) to re-enter the Chinese market. These include a heavy reliance on contraband, undermining of national advertising restrictions through local contacts, and influencing of policymaking through appeals to historical precedent and corporate social responsibility.

- Competing with kreteks: transnational tobacco companies, globalisation, and Indonesia. The first analysis of industry documents on Indonesia, explaining the difficulties encountered by the transnational companies in competing with the local kretek cigarettes, and highlighting challenges confronting tobacco control.

- Complicity in contraband: British American Tobacco and cigarette smuggling in Asia offers the first comprehensive regional analysis of corporate documents focused on smuggling, highlighting how BAT sought to direct this illicit trade and its critical role in corporate strategy.

- "Almost a role model of what we would like to do everywhere": British American Tobacco in Cambodia highlights BAT's exploitation of a desperate need for foreign investment, and the importance of Cambodia to its regional objectives.

- ARTIST (Asia Regional Tobacco Industry Scientist Team): Philip Morris' attempt to exert a scientific and regulatory agenda on Asia. The Asian tobacco scene has changed from an environment of invasion by transnational tobacco companies to one of collaboration between the transnational companies and local tobacco monopolies and companies, which often bring direct links with governments.

Correspondence to: Dr Judith M Mackay, Asian Consultancy on Tobacco Control, Hong Kong SAR; jmackay@pacific.net.hk

\section{REFERENCES}

1 Pollay RW, ed. Discoveries and disclosures in the corporate documents. Tobacco Control 2002;11(suppl I):i1-116. 
2 Malone R, ed. "One of the darkest markets in the world" - insights from Australian tobacco industry documents. Tobacco Control 2003;12(suppl III): iii $1-112$.

3 Hirschhorn N. Research reports and publications based on tobacco industry documents, 1995-2004. http://www.globalink.org/tobacco/docs/ secretdocs/2004hirschhorn_tobacco_documents_publication_list_1995_to_ 2004.htm.

4 Hurt RD, Robertson CR. Health law and ethics: prying open the door to the tobacco industry's secrets about nicotine: the Minnesota tobacco trial. JAMA 1998;280:1173-81

5 Hirschhorn N. Four decades of the tobacco industry's hidden research on smoking and health (Internet communication, 5 September 1999, at GLOBALink website http://www.globalink.org/ globdemo).
6 The Global Youth Tobacco Survey Collaborative Group. Tobacco use among youth: a cross country comparison. Tobacco Control 2002;11:252-70.

7 Global Youth Collaborating Group. Special report: differences in worldwide tobacco use by gender: findings from the Global Youth Tobacco Survey. J School Health 2003;73(6):207-215.

8 World Bank. Development in practice. Curbing the epidemic: governments and the economics of tobacco control. Washington DC: The World Bank, May 1999.

9 Mackay J. Commentary: lessons from private statements of the tobacco industry. Bull World Health Organ 2000;78:911-12.

10 Ciresi MV, et al. Decades of deceit: document discovery in the Minnesota tobacco litigation. William Mitchell Law Review 1999;25.

11 Bero L. Implications of the tobacco industry documents for public health and policy. Ann Rev Public Health 2003;24:267-88. 